$7-15-2020$

\title{
Self-help groups: A potential pivot of Bihar's response to COVID-19
}

UNICEF

Population Council Institute

Follow this and additional works at: https://knowledgecommons.popcouncil.org/departments_sbsr-pgy

Part of the Demography, Population, and Ecology Commons, International Public Health Commons, and the Public Health Education and Promotion Commons How does access to this work benefit you? Let us know!

\section{Recommended Citation}

UNICEF and Population Council Institute. 2020. "Self-help groups: A potential pivot of Bihar's response to COVID-19," COVID-19 Research Results Brief \#7. New Delhi: UNICEF and Population Council. 


\section{SELF-HELP GROUPS: A POTENTIAL PIVOT OF BIHAR'S RESPONSE TO COVID-19}

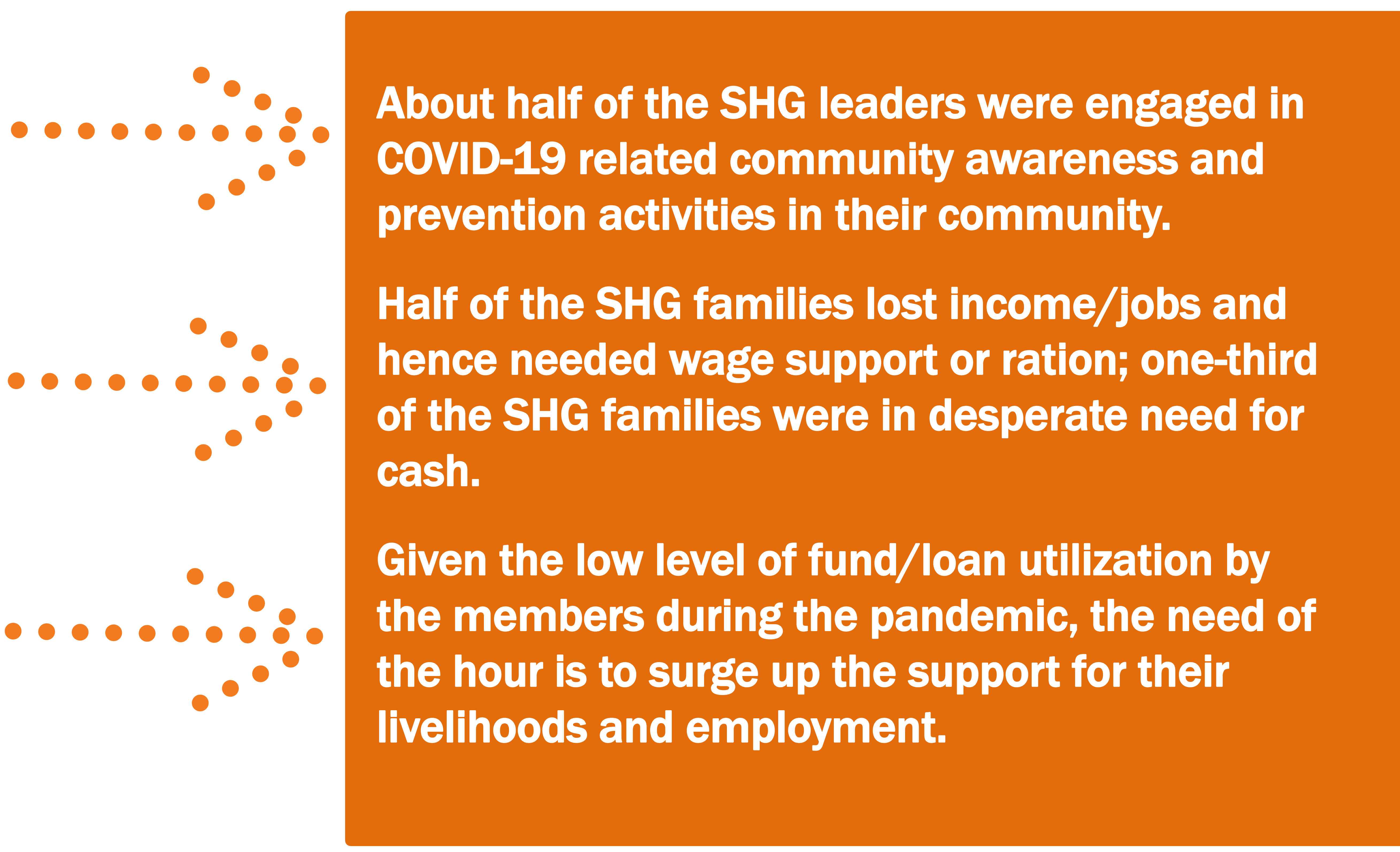

\section{SHG ENGAGEMENT}

- $49 \%$ SHG leaders reported that they were engaged in COVID-19 related community awareness and infection prevention activities in their community.

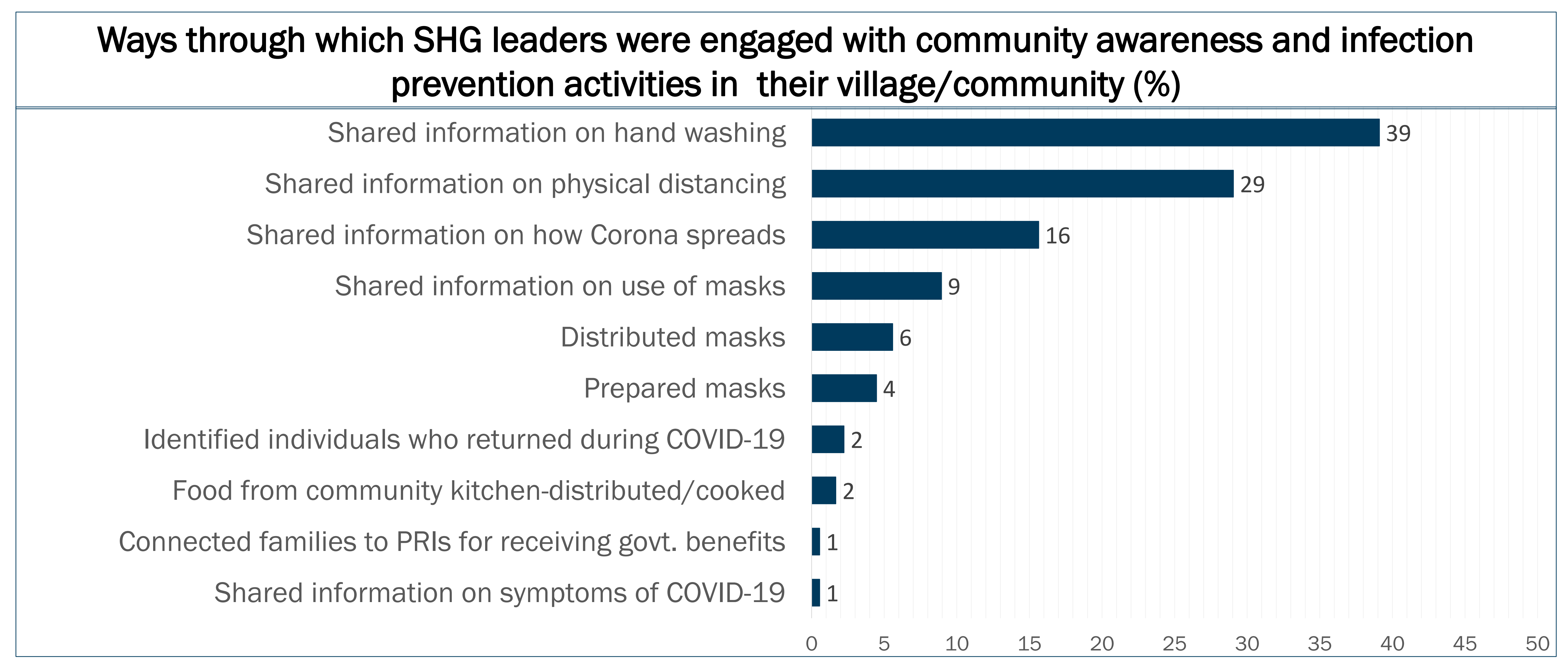

- $17 \%$ SHG leaders coordinated with gram panchayat (GP)/frontline health workers (FLWs)/block development office (BDO) in preventing the spread of COVID-19.

SHG leader's coordination with GP/ FLWs/ BDOs in preventing spread of COVID-19 (\%)

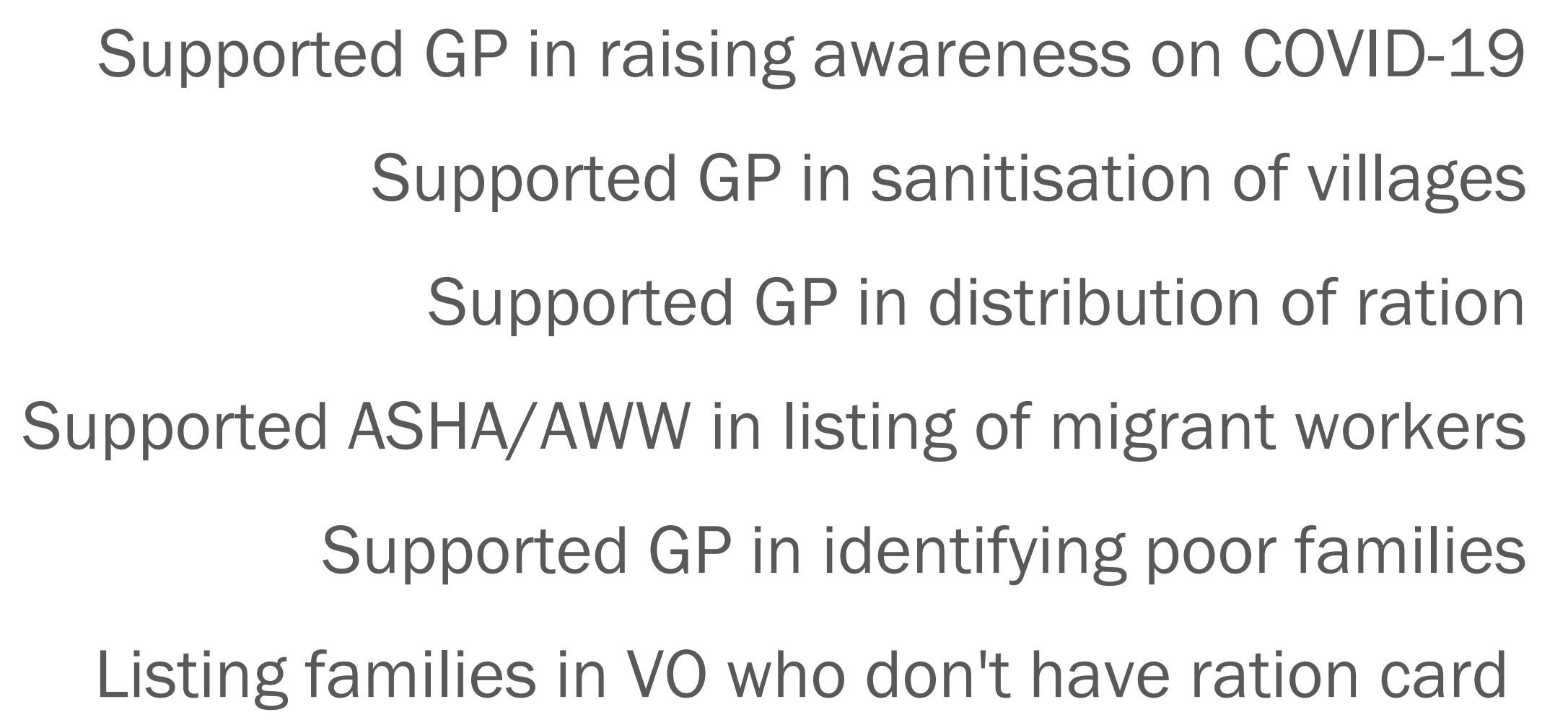

\section{ECONOMIC VULNERABILITY OF SHG MEMBERS}

Lost income/jobs \&
need wage support or
ration
$50 \%$ of the SHG
families have lost
income/jobs and
hence needed wage
support or ration
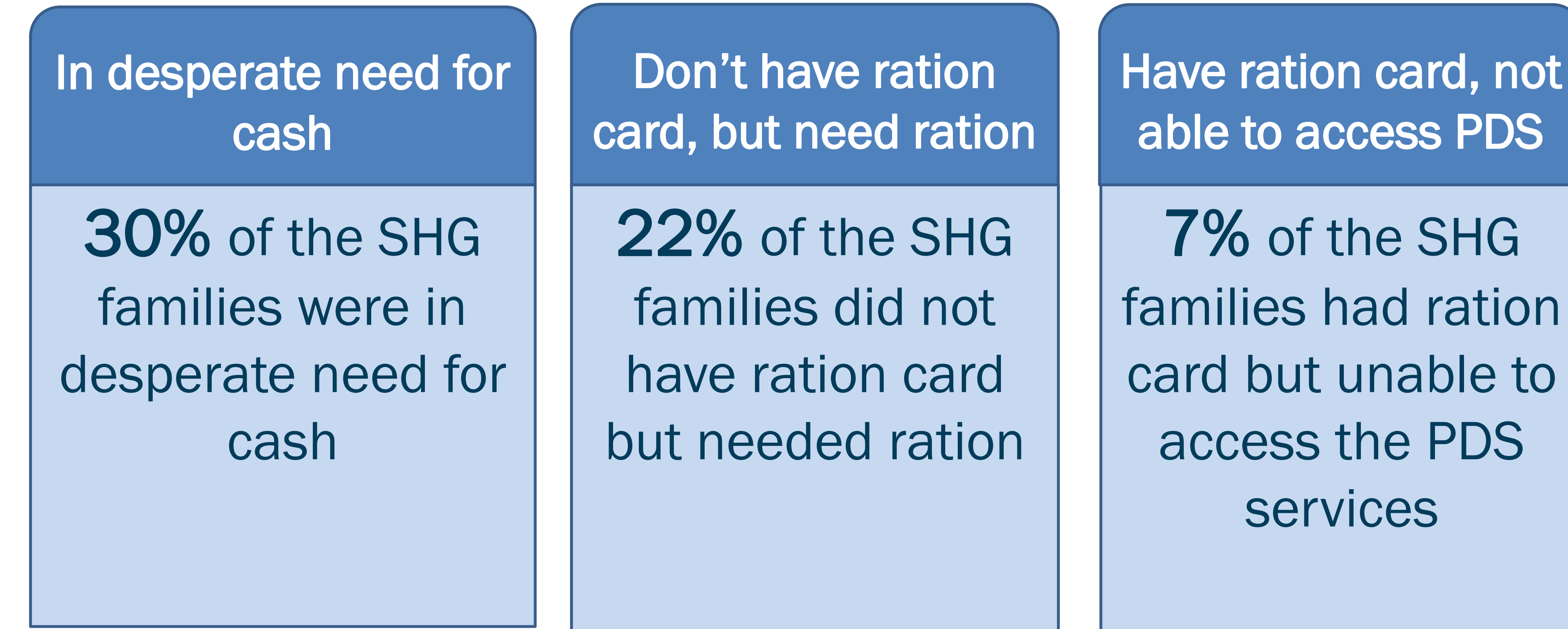

\section{SUPPORT TO MEMBERS THROUGH FUNDS AND LOANS}

- $6 \%$ SHG leaders reported that food security fund was given to their members and almost all members from those groups availed the benefit.

- 5\% SHG leaders informed that at least one member from their group took a loan during lockdown to buy food items, to manage 'no income' or for survival.

\section{LIMITATIONS}

Given the limited sample size, the results should be interpreted with caution, and the estimates may not be generalised. The constraints on the number of questions and time for a telephone survey restricted collecting additional information on economic vulnerability, which could help us gain more insights into the coping mechanisms.

\section{CONTACT INFORMATION}

This work was jointly undertaken by Population Council Institute and UNICEF/Bihar. For more information, contact akastor@popcouncil.org; nsaggurti@popcouncil.org; pash@unicef.org 